\title{
Carlo Sommerweizen e.K. stellt sich vor
}

Carlo Sommerweizen (46 Jahre) ist ein erfolgreicher Einzelunternehmer. Neben seinem Kfz-Handel betreibt er eine angeschlossene Reparaturwerkstatt (und das mittlerweile sehr erfolgreich). Zu Beginn seiner Tätigkeit -vor einigen Jahrenbeschäftigte sich Carlo intensiv u.a. mit den Bereichen Buchführung (Grundlagen), Betriebssteuern, Kostenrechnung und Jahresabschlusserstellung. Nun, nachdem er über fundiertes Wissen im Grundlagenbereich verfügt, möchte er sich noch weitere, tiefer gehende Kenntnisse verschaffen.

Dazu wählte er in den vergangenen Monaten viele Themengebiete aus, die er in Zusammenarbeit mit seinem Steuerberater bearbeitet hat.

Nun halten Sie das vorliegende Buch mit zahlreichen Beispielen, Kontrollfragen und Übungen in Händen, welches Ihnen ebenfalls eine hilfreiche Unterstützung im Arbeitsalltag sein soll. Ein Anspruch auf Vollständigkeit wird nicht erhoben. 